\title{
ASSISTÊNCIA DE ENFERMAGEM HUMANIZADA EM INSTITUIÇÕES DE LONGA PERMANÊNCIA PARA IDOSOS
}

\author{
HUMANIZED NURSING CARE IN LONG-STAY INSTITUTIONS FOR \\ THE ELDERLY
}

\author{
Antônio Levi Sampaio de Araújo ${ }^{1}$ \\ Francisco Weverton Carneiro Gomes ${ }^{2}$ \\ Gabriel Pereira Fidelis ${ }^{3}$ \\ Jefferson Washington de Souza Rodrigues ${ }^{4}$ \\ José Valdilânio Virgulino Procópio ${ }^{5}$ \\ Marcus Vinícius Leite Batista Lacerda ${ }^{6}$
}

RESUMO: Este trabalho tem como objetivo descrever a importância da assistência de enfermagem ao idoso institucionalizado baseando-se nos princípios de humanização. Trata-se de uma revisão narrativa da literatura, realizada através da busca de artigos sobre o tema abordado nas bases de dados Literatura LatinoAmericana e do Caribe em Ciências da Saúde (LILACS), Medical Literature Analvsis and Retrieval System Online (MEDLINE), Base de dados bibliográficos especializada na área de Enfermagem (BDENE) e Index Psicologia, sendo selecionado no final 07 artigos publicados nos últimos cinco anos entre 2014 a 2018 para servirem de base para construção deste estudo, desenvolvido nos meses de setembro a novembro de 2019. Evidenciamos que o principal responsável por promover cuidados humanizados e uma assistência de qualidade é o enfermeiro e para isso acontecer é necessário que esse profissional conheça as necessidades e limitações de cada indivíduo, sendo capaz de estabelecer vínculos de confiança com o idoso.

Palavras chave: Enfermagem. Longa permanência. Idosos. Instituição.

ABSTRACT: This paper aims to describe the importance of nursing care for institutionalized elderly people based on the principles of humanization. This is a narrative review of the literature, conducted through the search for articles on the

\footnotetext{
${ }^{1}$ Acadêmico de Medicina da Faculdade Santa Maria.

2 Acadêmico de Medicina da Faculdade Santa Maria.

${ }^{3}$ Acadêmico de Medicina da Faculdade Santa Maria.

${ }^{4}$ Acadêmico de Medicina da Faculdade Santa Maria.

${ }^{5}$ Acadêmico de Medicina da Faculdade Santa Maria.

${ }^{6}$ Acadêmico de Medicina da Faculdade Santa Maria.
} 
topic addressed in the databases Latin American and Caribbean Health Sciences (LILACS), Medical Literature Analysis and Retrieval System Online (MEDLINE), Bibliographic database specialized in the area of Nursing (BDENE) and Index Psychology, being selected at the end 07 articles published in the last five years from 2014 to 2018 to serve as basis for the construction of this study, developed from September to November 2019. We evidenced that the main responsible for promoting humanized care and quality care is the nurse and for this to happen it is necessary that this professional knows the needs and limitations of each individual, being able to establish bonds of trust with the elderly.

Keywords: Nursing. Long stay. Seniors. Institution. 


\section{INTRODUÇÃO}

Até o ano 2025 a população de idosos no Brasil crescerá 16 vezes, contra cinco vezes da população total, classificando o país como a sexta população do mundo em números de idosos (OMS, 2005).

Com o passar dos anos o avançar da idade vai acontecendo e precedida a ela, alterações estruturais e funcionais em todos os idosos, efeitos normais do processo de envelhecimento. Não há dúvidas que estas alterações afetam as habilidades e manutenção da independência do indivíduo, os tornando assim, na maioria das vezes, impossibilitados de decidir o que the é mais conveniente (DIAS; RENATA, 2016).

O processo de envelhecimento é associado a imagens negativas de doença, incapacidade, desprazer e terminalidade que muitas vezes culmina com a morte social do idoso. Gradativamente é preciso que os idosos recebam um atendimento mais humanizado e especializado, pelas próprias condições que ele apresenta, condições de senilidade onde adentra perda da memória, funções auditivas ou visuais não são mais as mesmas, além de alterações de coordenação motora (PEREIRA, 2017).

Devido as alterações da capacidade funcional, o idoso exige maior cuidados. $E$ atualmente, o que se observa é que muitos desses idosos vivem com intenso sofrimento, doenças crônicas incapacitantes e em extrema pobreza. A família, é um componente indispensável nestas condições, pois para o paciente o ambiente familiar se torna um local de proteção e estabilidade. A atenção prestada e o cuidar vão muito além do atendimento as necessidades básicas do ser humano, visa a sua integralidade como um todo. Muitos idosos, não dispõem de condições para permanecer com suas famílias em seus domicílios, optando então, pelas instituições de longa permanência para idosos (ILPIs), (VERAS, 2018).

Instituições governamentais ou não governamentais de caráter residencial, destinadas a serem domicílios coletivos de pessoas com idade igual ou superior a 60 
anos, com ou sem suporte familiar, em condição de liberdade, dignidade e cidadania" (ROZENDO; OLIVEIRA, 2014).

Por meio da situação de vulnerabilidade, carência, a falta de assistência humanizada, em alguns casos maus tratos e abandono familiar, é progressiva a necessidade de valorização do paciente idoso, no atendimento de enfermagem para promoção de saúde nas ILPI (PINHO et al., 2017).

Apesar de o termo humanização atualmente se faça presente em várias discussões, os pacientes idosos ainda encaram frequentemente vários obstáculos para assegurar assistência à saúde de forma humanizada (BRASIL, 2015).

Humanizar em saúde é atender as necessidades do outro com responsabilidade e entender os diversos enfoques envolvidos nas dinâmicas da vida dos clientes, reconhecendo seus direitos, sua história e seus sentimentos, pois o termo humanização é concebido como atendimento das necessidades integrais do indivíduo e necessidades humanas básicas (PEREIRA, 2017).

"A humanização dos cuidados em saúde pressupõe considerar a essência do ser, o respeito à individualidade e a necessidade da construção de um espaço concreto nas instituições de saúde que legitime o humano das pessoas envolvidas" (PESSINI, 2004).

Todo ser humano tem direito ao atendimento público de qualidade e uma assistência humanizada, e ao cuidado individualizado. $\mathrm{Na}$ saúde existe uma carência no tratamento humanizado, então a Política Nacional de Humanização (PNH) existe desde 2003 para efetivar os princípios do SUS no cotidiano das práticas de atenção e gestão, qualificando a saúde pública no Brasil e incentivando trocas solidárias entre gestores, trabalhadores e usuários. A PNH possui diretrizes capazes de humanizar o cuidado e o cuidar, como pressuposto para atuar diretamente na recuperação e reabilitação dos mesmo a vida social, promovendo maior qualidade de vida e estimulando o autocuidado (BRASIL, 2015).

O profissional de enfermagem tem papel de fundamental importância nesse processo, geralmente é o principal responsável por promover cuidados humanizados e uma assistência de qualidade ao idoso e para isso acontecer é essencial que conheça as necessidades e limitações de cada paciente, sendo capaz de estabelecer um vínculo de empatia e confiança com o idoso (PEREIRA, 2017). 
Quando o enfermeiro atua junto à pessoa idosa residente em uma ILPI, esse trabalhador tem condições de tornar esse cuidado mais humanizado, acolhedor, avaliativo, integral, podendo contribuir para melhoria da qualidade de vida do idoso institucionalizado (SANTO, 2008).

$\mathrm{Na}$ tentativa de encontrar respostas à pergunta "Qual a importância de um atendimento de enfermagem humanizado para idosos em instituições de longa permanência?"

Este estudo oferecerá subsídios para a compreensão da importância do atendimento humanizado em instituições de longa permanência para idosos, bem como poderá contribuir diante da necessidade da ampliação de conhecimento acadêmico. O conhecimento, por parte da equipe de enfermagem, da importância deste atendimento humanizado e os benefícios que serão proporcionados aos idosos, será fator estimulante para as práticas humanizadas.

\section{OBJETIVOS}

Descrever a importância da assistência de saúde aos idosos de instituições de longa permanecia tendo como base os princípios de humanização. Assim como evidenciar através da literatura, acerca do cuidado humanizado ao idoso disseminada em períodos online do âmbito de saúde. Além de destacar o que uma assistência humanizada pode promover na vida dos idosos institucionalizados.

\section{METODOLOGIA}

Foi adotada como estratégia metodológica a revisão narrativa que é um dos tipos de revisão de literatura, permite o relato de outros trabalhos, a partir da compreensão do pesquisador sobre como os outros fizeram. 
A revisão narrativa de literatura, possui caráter amplo e se propõe a descrever o desenvolvimento de determinado assunto, sob o ponto de vista teórico ou contextual, mediante análise e interpretação da produção científica existente. Essa síntese de conhecimentos a partir da descrição de temas abrangentes favorece a identificação de lacunas de conhecimento para contribuir com a realização de novas pesquisas (HIRT, 2016).

A busca pela construção da pesquisa se deu com a necessidade de conhecer mais acerca da importância da assistência de enfermagem aos idosos de instituições de longa permanência tendo como base os princípios de humanização.

A pesquisa foi desenvolvida através de explorações eletrônicas buscando artigos de acordo com o tema em questão, na Biblioteca Virtual de Saúde (BVS), as bases de dados utilizadas foram: Literatura Latino-Americana e do Caribe em Ciências da Saúde (LILACS), Medical Literature Analvsis and Retrieval System Online (MEDLINE), Base de dados bibliográficos especializada na área de Enfermagem (BDENE) e Index Psicologia, onde foram utilizados como descritores para busca: "Instituição de longa permanência para idosos" AND "Enfermagem".

Os critérios de inclusão definidos para a seleção dos artigos foram: artigos que retratam a temática, no idioma português, no formato: artigo, completos e originais, dos últimos 5 anos (2014-2018), disponíveis na integra.

Em relação aos critérios de exclusão foram os artigos que não retratam as questões e problematizações referentes ao assunto em questão.

Os resultados foram agrupados em quadro contendo as seguintes informações: Título do artigo, ano de publicação, objetivos, principais resultados e conclusões. E por fim, foi realizada a discussão com base nos resultados, estes separados por domínios temáticos: 1) Envelhecimento, 2) Instituição de Longa Permanência para Idosos, 3) Humanização em Saúde, 4) Assistência de enfermagem humanizada aos idosos institucionalizados.

Os artigos foram avaliados criticamente de acordo com o conteúdo abordado no estudo. 


\section{RESULTADOS}

Tabela 1 - Resultados da pesquisa.

\begin{tabular}{|c|c|c|c|c|}
\hline TÍTULO & ANO & OBJETIVOS & $\begin{array}{l}\text { PRINCIPAIS } \\
\text { RESULTADOS }\end{array}$ & CONCLUSÃO \\
\hline $\begin{array}{l}\text { Exercício } \\
\text { profissional } \\
\text { de } \\
\text { enfermagem } \\
\text { em } \\
\text { instituiçãoes } \\
\text { de longa } \\
\text { permanência }\end{array}$ & 2018 & $\begin{array}{l}\text { Avaliar } \\
\text { resultados } \\
\text { fiscalização ético da } \\
\text { profissional } \\
\text { enfermagem em } \\
\text { nstituições } \\
\text { Longa Permanência } \\
\text { para Idosos. }\end{array}$ & $\begin{array}{l}\text { O envelhecimento dal } \\
\text { população e ai } \\
\text { crescente ênfase nos } \\
\text { cuidados de saúde } \\
\text { prolongados denotam } \\
\text { que um número aindai } \\
\text { maior de idosos deve } \\
\text { necessitar } \\
\text { Cuidados de } \\
\text { enfermagem nas ILPI } \\
\text { no futuro. }\end{array}$ & $\begin{array}{l}\text { aDevem ser implementadas } \\
\text { aintervenções que garantam um } \\
\text { ssistema seguro de assistência. } \\
\text { elsto se baseia nas iniciativas que } \\
\text { ncada serviço pode começar a } \\
\text { aimplementar a partir de gestão } \\
\text { ediária, contribuindo para a } \\
\text { equalidade da assistência em torno } \\
\text { eda segurança Dos pacientes, } \\
\text { Plsatisfação do idoso e família e } \\
\text { inclusão da ILPI na esfera social. }\end{array}$ \\
\hline $\begin{array}{l}\text { A } \\
\text { humanização } \\
\text { da } \\
\text { assistência } \\
\text { na ótica de } \\
\text { profissionais } \\
\text { de } \\
\text { enfermagem } \\
\text { que cuidam } \\
\text { de idosos }\end{array}$ & 2017 & $\begin{array}{l}\text { Desvelar a vivência } \\
\text { do profissional de } \\
\text { enfermagem no } \\
\text { desenvolvimento do } \\
\text { cuidado e do } \\
\text { relacionamento com } \\
\text { idosos } \\
\text { institucionalizados. }\end{array}$ & $\begin{array}{l}\text { O cuidado ao idoso } \\
\text { na ILPI, cenário do } \\
\text { estudo, foi avaliado } \\
\text { positivamente. Os } \\
\text { profissionais } \\
\text { enfermagem de } \\
\text { consideraram } \\
\text { assistência } \\
\text { humanizada, } \\
\text { verificaram-se } \\
\text { episódios em que } \\
\text { estes trabalhadores } \\
\text { perceberam que a } \\
\text { humanização está } \\
\text { ancorada ao cuidado. }\end{array}$ & $\begin{array}{l}\text { o } \\
0 \\
0 \\
\text { s } \\
\text { e } \text { Os profissionais de enfermagem } \\
\text { perceberam a humanização da } \\
\text { assistência como um modo de ser } \\
\text { ecom o outro, ou seja, proximidade, } \\
\text { ecompromisso, interação, respeito, } \\
\text { eautonomia e valorização do idoso. } \\
\text { s } \\
\text { a } \\
\text { á }\end{array}$ \\
\hline $\begin{array}{l}\text { A } \\
\text { enfermagem } \\
\text { dá o tom no } \\
\text { atendimento } \\
\text { humanizado } \\
\text { aos idosos } \\
\text { institucionaliz } \\
\text { ados? }\end{array}$ & 2016 & $\begin{array}{l}\text { O presente artigo } \\
\text { nasceu no interesse } \\
\text { de conhecer a } \\
\text { reflexão } \\
\text { enfermeiras sobre a } \\
\text { humanização nos } \\
\text { cuidados que } \\
\text { prestam aos idosos } \\
\text { nas ILPIs }\end{array}$ & $\begin{array}{l}\text { Ao compreender o } \\
\text { significado da vida no } \\
\text { processo de cuidar, o } \\
\text { profissional há de } \\
\text { aultrapassar as } \\
\text { atribuições técnicas, } \\
\text { para desenvolver a } \\
\text { capacidade re } \\
\text { acolher o ser } \\
\text { humano, sua história } \\
\text { de vida eseus } \\
\text { sentimentos. }\end{array}$ & $\begin{array}{l}\text { o } \\
{ }^{o} \\
{ }^{\circ} \text { A assistência nas instituições não } \\
\text { sé híbrida, é explicitamente social, } \\
\text { ou seja, é um serviço que deve ser } \\
\text {, de interesse à saúde. Portanto, é } \\
\text { erucial reconhecer que a } \\
\text { erinstituição não pode funcionar com } \\
\text { a base na lógica hospitalar. } \\
\text { s }\end{array}$ \\
\hline
\end{tabular}




\begin{tabular}{|c|c|c|}
\hline $\begin{array}{l}\text { O cuidar de } \\
\text { pessoas } \\
\text { idosas } \\
\text { institucionaliz } \\
\text { a das na } \\
\text { percepção da } \\
\text { equipe de } \\
\text { enfermagem }\end{array}$ & 2015 & 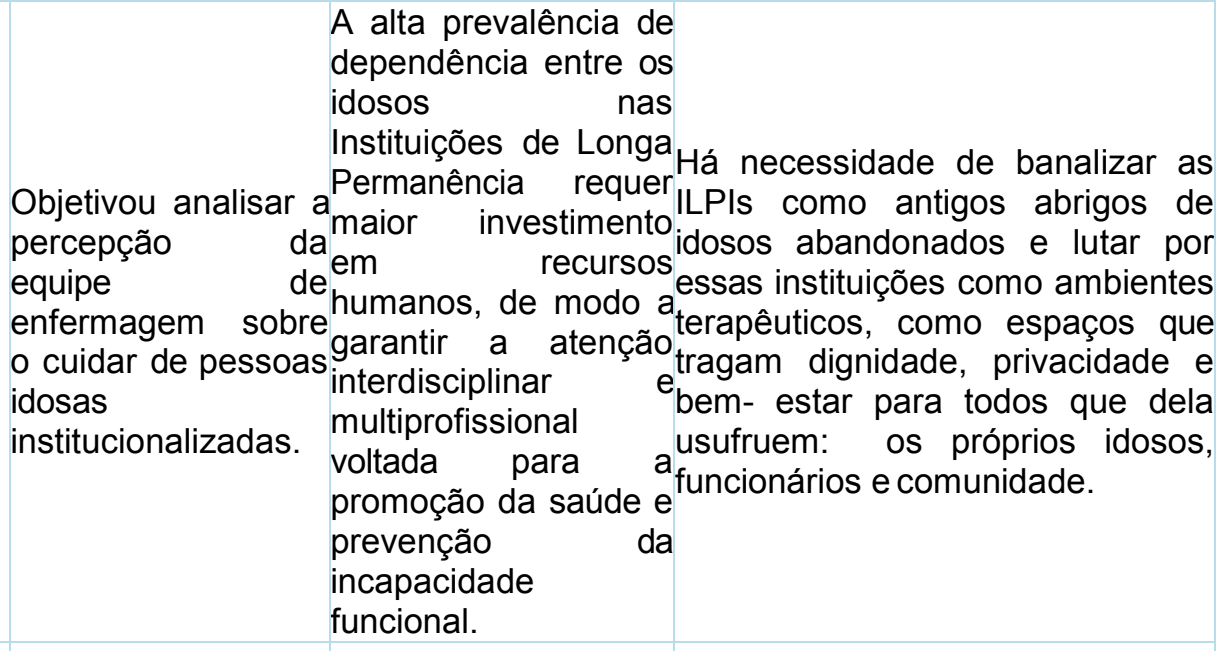 \\
\hline $\begin{array}{l}\text { Condições de } \\
\text { saúde de } \\
\text { idosos } \\
\text { residentes em } \\
\text { instituições } \\
\text { de longa } \\
\text { permanências } \\
\text { egunda } \\
\text { necessidades } \\
\text { humanas } \\
\text { básicas. }\end{array}$ & 014 & 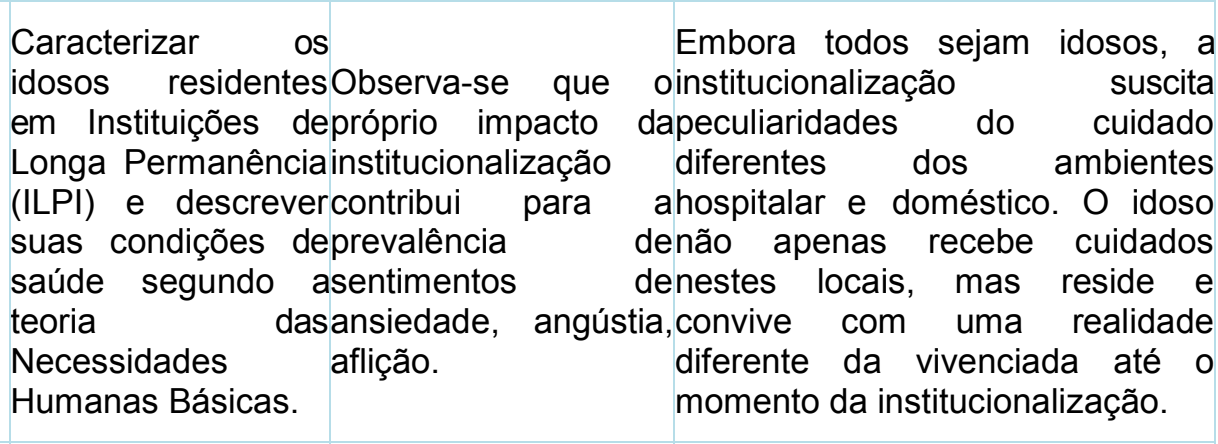 \\
\hline $\begin{array}{l}\text { Instituição de } \\
\text { longa } \\
\text { permanência } \\
\text { para idosos: } \\
\text { um lugar para } \\
\text { quem não } \\
\text { tem opção? }\end{array}$ & 2014 & 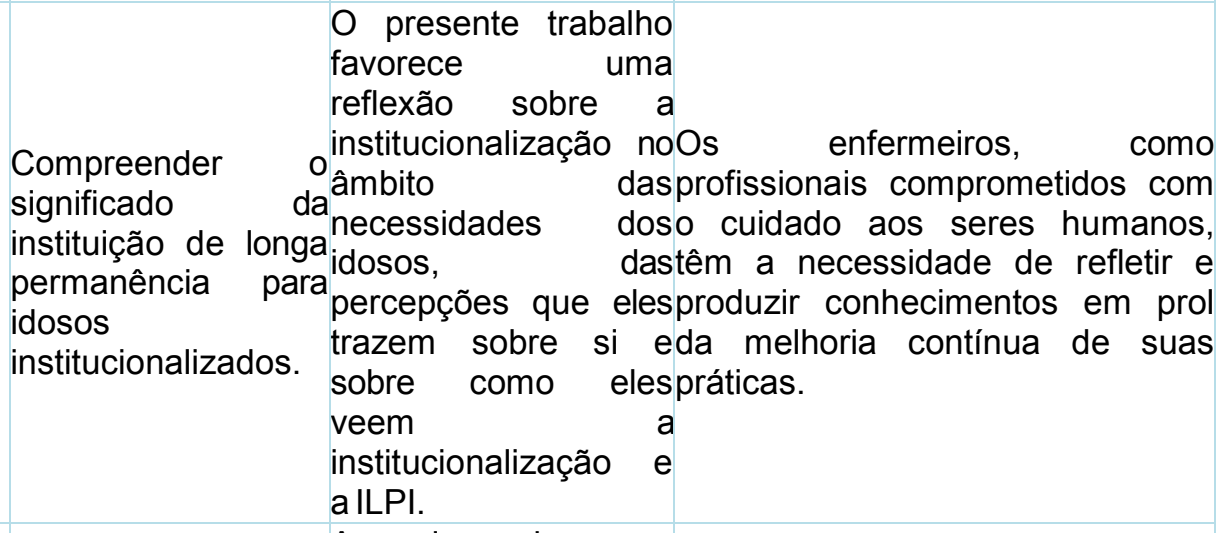 \\
\hline $\begin{array}{l}\text { Uso do tempo } \\
\text { livre através } \\
\text { de recursos } \\
\text { expressivos: } \\
\text { contribuição } \\
\text { para um } \\
\text { grupo de } \\
\text { idosos } \\
\text { institucionaliz } \\
\text { ados. }\end{array}$ & 2014 & 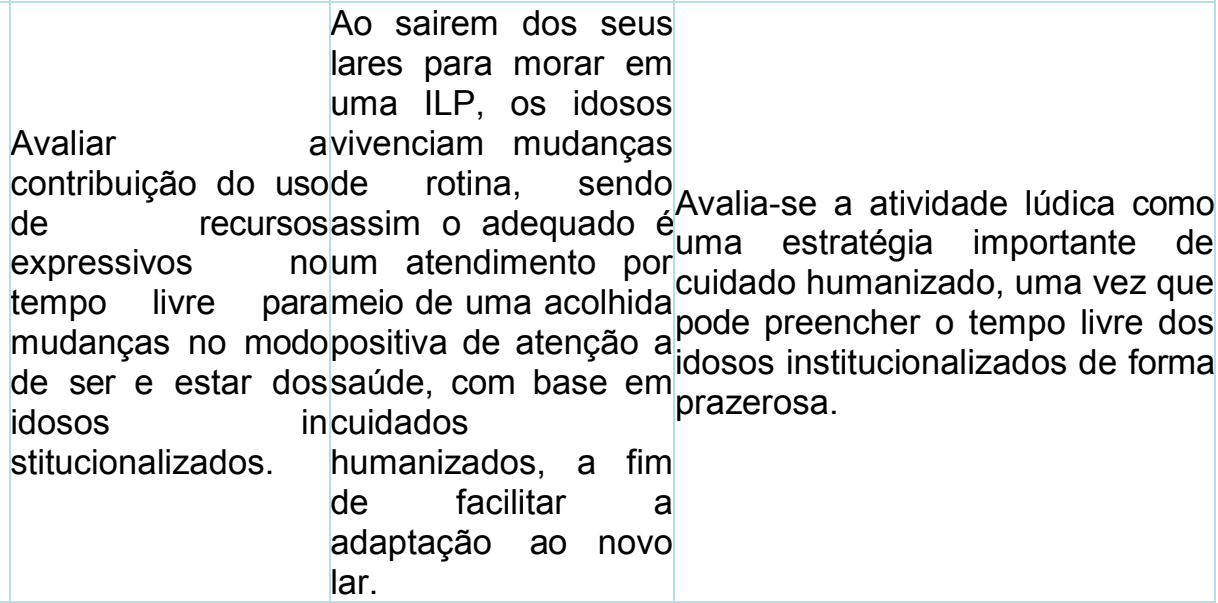 \\
\hline
\end{tabular}




\section{DISCUSSÃO}

Percebeu-se ao analisar os artigos que poucos se encontraram no item de inclusão, devido muitos terem sido excluídos pelo idioma ser em inglês ou anterior ao ano de 2014.

Em relação aos artigos utilizados neste trabalho, 3 artigos foram elaborados em 2014, 1 em 2015, 1 em 2016, 1 artigo foi produzido em 2017 e 1 artigo em 2018. As áreas temáticas observadas no estudo julgadas importantes e relevantes para destacar a importância de uma assistência humanizada em instituições de longa permanência para idosos.

Dos artigos selecionados, esses foram organizados por tema trabalhado e elaborado 4 categorias que se destacam em: Envelhecimento; Instituição de longa permanência para idosos; Humanização em Saúde e Assistência de enfermagem humanizada aos idosos institucionalizados.

As categorias foram descritas na tabela 2 para facilitar a temática e organizar melhor as discussões a serem esclarecidas.

Tabela 2 - Categorias da pesquisa.

\begin{tabular}{|l|l|}
\hline \multirow{4}{*}{ CATEGORIAS } & Envelhecimento \\
\cline { 2 - 2 } & Instituição de longa permanência para idosos \\
\cline { 2 - 3 } & Humanização em Saúde \\
\cline { 2 - 2 } & Assistência de enfermagem humanizada \\
\hline
\end{tabular}

\section{Primeira Categoria: Envelhecimento}

Envelhecer, ainda que sem doenças crônicas, envolve alguma perda funcional que pode afetar diretamente a saúde do idoso, comprometendo sua capacidade física e mental, como dificuldade para exercer atividades diárias, maior propensão para quedas, movimentos lentos e como consequência sentimentos de 
inutilidade. Com tantas situações adversas, o cuidado do idoso deve ser estruturado de forma diferente. (OLIVEIRA; ROZENDO, 2014).

O envelhecimento pode ser compreendido com a interação de diferentes aspectos cronológicos, biológicos, psicológicos e sociais na vida de um indivíduo que ao longo do tempo torna-se mais vulnerável e suscetível a doenças. (TAVARES; OLIVEIRA, 2014).

A população do Brasil está envelhecendo. Em 2015, o IBGE apontou que $14,3 \%$ da população do país tinha mais de 60 anos. Com esse aumento da população idosa e das dificuldades dos familiares em assumir a tarefa de cuidar, a busca por Instituições de Longa Permanência para Idosos (ILPI), incluindo os asilos e as casas de repouso, tende a aumentar, questão que preocupa a sociedade e os órgãos de classe no que diz respeito a regularização das ILPI, que surgem em abundancia e de modo precário no cenário brasileiro. (RODRIGUES et al., 2018).

\section{Segunda Categoria: Instituição de longa permanência para idosos}

As ILPI são um tipo de rede de apoio de caráter residencial, destinada a domicílio coletivo para pessoas idosas (acima de 60 anos), com ou sem auxilio familiar. São domicílios que surgem como alternativa de suprir as necessidades de cuidados e serviços de saúde a essa população. Envolve não só a assistência à saúde, mas também o ambiente de moradia e social. (MEDEIROS et al., 2015).

Em decorrência do aumento do número de idosos e da longevidade da população, as famílias começam a ter dificuldade de cuidar dos idosos no próprio lar. Em consequência ao surgimento de novos membros familiares, da inserção no mercado de trabalho, assim como, do próprio tempo de cuidar. Esta realidade resulta em um forte impacto na rede de proteção aos idosos e é notória o aumento da procura por essas instituições.

De acordo com Oliveira, Rozendo (2014), em seu estudo, onde foram entrevistados 13 idosos institucionalizados, para eles, uma ILP consiste em um lugar onde são cuidados e acolhidos, refere-se a envelhecer tendo acesso a serviços e 
recursos que atendam suas necessidades básicas como alimentação, higiene, moradia e lazer.

Oliveira, Concone e Souza (2016) observaram que o enfrentamento das barreiras que levam à incapacidade e ao isolamento do indivíduo requer ação coletiva para que o ambiente institucional seja favorável à sua saúde e à sua vida. Cabe às ILPI permitirem uma oferta de cuidados que acolha, entenda e atenda o morador, incentivando suas escolhas e respeitando sua individualidade; aos profissionais cabe inovarem em formas de participação e acessibilidade, para que o ambiente físico, social e de atitudes da instituição contribua para o alcance de um melhor potencial físico e psicológico.

\section{Terceira Categoria: Humanização em saúde}

De acordo com Oliveira Concone e Souza (2016) Humanização é o ato de cuidar, preocupar-se com o bem-estar do próximo. "Humanizar" significa tornar benéfico, oferecer condições humanas de vida, tratar com dignidade, respeitando as condições e individualidade da pessoa. A humanização no âmbito da saúde deve ser analisada tendo em vista adequá-la como uma assistência que considere o indivíduo na sua totalidade.

A humanização está relacionada ao cuidado, não é algo que ocorre de forma automática, necessita ser aprendida e praticada, significa cuidar como gostaria de ser cuidado, levando em consideração seus sentimentos, limitações e crenças, não tratando apenas pela doença, também pelo emocional, promovendo um ambiente acolhedor. (OLIVEIRA et al., 2017). 


\section{Quarta Categoria: Assistência de enfermagem humanizada}

Com relação à institucionalização, há de se considerar que os idosos, ao saírem dos seus lares para morarem em uma ILP, precisam lidar com muitas mudanças como: alteração da rotina, abandono de alguns dos hábitos adquiridos, diferenciação da alimentação, convivência com pessoas estranhas e a diminuição da proximidade com seus familiares. Situações vivenciadas como estas, exigem um atendimento adequado por meio de uma acolhida positiva de atenção à saúde, com base em cuidados humanizados, a fim de facilitar a adaptação ao novo lar (BALLA; MOURA, 2014).

Embora todos sejam idosos, a institucionalização, suscita peculiaridades do cuidado diferentes dos ambientes hospitalar e doméstico. $O$ idoso não apenas recebe cuidados nestes locais, mas reside e convive com uma realidade diferente da vivenciada até o momento da institucionalização. Oferecer esse cuidado ao idoso significa compreendê-lo no seu próprio espaço e favorecer a empatia nos encontros dentro do espaço onde ele reside, neste caso o ambiente institucional (TAVARES; OLIVEIRA, 2014).

Sabemos que geralmente o enfermeiro é o principal responsável para promover uma assistência adequada no atendimento, usando seu conhecimento e elaborando estratégias para atender melhor esse público que aumenta cada vez mais.

Segundo Medeiros Et. al (2015) O cuidar é uma atividade que vai muito além do atendimento as necessidades básicas do ser humano, no momento de fragilidade. Cuidar é uma atitude que envolve também autocuidado, autoestima, autovalorização.

Alguns indicadores para manter um processo de humanização são por exemplo: atitudes de empatia, se colocando no lugar do outro, desenvolver a relação de ajuda com relações de confiança e carinho, estar disposto a escutar atentamente suas queixas, medos e inseguranças, deixando expressar seus sentimentos positivos e negativos, respeitar seus valores e crenças, examinar de maneira 
atenciosa pedindo permissão para despir e tocar o paciente, propiciando um ambiente que respeite a dignidade humana, bem como manter contato visual durante o processo de comunicação.

Atitudes como essas podem ajudar a estabelecer vínculos de confiança, facilitando o cuidado ao paciente idoso, além de servir para valorizá-lo como ser especial, sem violar sua privacidade.

A enfermagem desempenha um papel importante, auxiliando o idoso a continuar bem, vencer ou enfrentar doenças, recuperando suas funções e encontrando sentido e finalidade a vida.

Portanto, a enfermagem como executora do cuidado, deve contemplar a humanização levando em conta as diferenças culturais, buscando adequar o cuidado necessário ao bem-estar do idoso institucionalizado. Sendo assim, é importante que, a mesma, estabeleça padrões próprios de atendimento levando em consideração as necessidades do indivíduo (OLIVEIRA et al., 2017).

\section{CONCLUSÕES}

De acordo com os artigos analisados após a revisão de estudos publicados referente ao tema em questão concluiu-se que práticas de humanização contribuem para a assistência de enfermagem de forma significativa, fazendo com que o enfermeiro veja o indivíduo além da doença que acomete o mesmo.

Embora o termo humanização atualmente se faça presente em várias discussões, os pacientes idosos ainda enfrentam cotidianamente vários obstáculos para assegurar assistência à saúde de forma humanizada. Assim, a atenção especial ao cuidado humanizado, pautados em teorias, facilitam o processo de compreensão e visualização do ser humano e profissional de enfermagem como um todo.

Ao tecer as conclusões deste trabalho, é importante expressar a certeza de seu inacabamento, visto não ter a pretensão de esgotar aqui as reflexões acerca do 
tema. Dessa forma deixa-se espaço para a continuidade e para possíveis retomadas das discussões.

Enfim os achados deste trabalho permitem maximizar os impactos da assistência humanizada dos profissionais enfermeiros a população idosa em instituições de longa permanência, destacando sua importância orientando-os sobre aspectos de humanização para oferecer uma assistência integral e holística.

Que esta pesquisa possa contribuir para ampliar a compreensão dos significados desse conceito "Humanização", bem como suas possibilidades de aplicação em pesquisas e nas práticas de saúde, e que os profissionais da saúde, trabalhem com mais amor ao próximo.

\section{REFERÊNCIAS BIBLIOGRÁFICAS}

AMORIM, Rosendo Freitas et al. A Formação Acadêmica dos Profissionais de Saúde Numa Perspectiva da Humanização dos Cuidados Paliativos: uma Metassíntese. Congresso Internacional de humanidade e humanização em saúde, Blucher Medical Proceedings, num.2, vol.1]. São Paulo: Editora Blucher, 2014. Disponivel em: <http://pdf.blucher.com.br.s3-saeast1.amazonaws.com/medicalproceedings/cihhs/10540.pdf>.

BALLA, Eliane; SCORTEGAGNA, Helenice de Moura. Uso do tempo livre através de recursos expressivos: contribuição para um grupo de idosos institucionalizados. Estud. interdiscipl. envelhec., Porto Alegre, v. 19, n. 2, p. 471-484, 2014. Disponivel em: https://seer.ufrgs.br/index.php/RevEnvelhecer/article/view/41294/32759.

COSTA, Arlete Eli Kunz et al. A percepção da equipe de enfermagem acerca do atendimento prestado ao idoso hospitalizado com dor. Caderno pedagógico, Lajeado, v. 12, n. 3, p. 38-51, $2015 . \quad$ Disponivel em: <HTTP://UNIVATES.BR/REVISTAS/INDEX.PHP/CADPED/ARTICLE/VIEW/968>.

DIAS, Kalina Coeli Costa Oliveira et al. Estratégias para humanizar o cuidado com o idoso hospitalizado: estudo com enfermeiros assistenciais. J. res.: fundam. care. online 2015. jan./mar. 7(1):1832-1846. Disponível em: <https://www.redalyc.org/html/5057/505750945008/>.

DIAS, Renata Fátima Ribeiro. Sistematização da Assistência de Enfermagem em uma instituição de longa permanência para idosos no interior do RS. Florianópolis, Santa Catarina, 2014. Disponível em: <https://repositorio.ufsc.br/handle/123456789/168524>.

GONÇALVES, Marcelo José Cirilo et al. A importância da assistência do enfermeiro ao idoso institucionalizado em instituição de longa permanência. São Paulo: Revista Recien. 2015; 5(14):12-18. Disponível em: <https://recien.com.br/index.php/Recien/article/view/106/172>.

MEDEIROS, Camyla Bernardo et al. A perspectiva do usuário na atenção básica sobre o acolhimento ao idoso. Revista Ciência Plural. 2018; 4(3):43-56. Disponível em: <https://periodicos.ufrn.br/rcp/article/view/17290/11361>.

MEDEIROS, Fabíola de Araújo Leite et al. O cuidar de pessoas idosas institucionalizadas na 
percepção da equipe de enfermagem. Rev Gaúcha Enferm. 2015 mar;36(1):56-61. Disponivel em: http://www.scielo.br/scielo.php?script=sci_arttext\&pid=\$0034-71672014000500773.

OLIVEIRA, Bernadete; CONCONE, Maria Helena Villas Bôas; SOUZA, Sandra Regina Pelisser. A Enfermagem dá o tom no atendimento humanizado aos idosos institucionalizados?. Revista Kairós Gerontologia, 19(1), pp. 239-254. ISSNe 2176-901X. São Paulo (SP), Brasil: FACHS/NEPE/PEPGG/PUC-SP, 2016.

Disponível em: $<$ https://revistas.pucsp.br/kairos/article/view/31112/21529>.

OLIVEIRA, Janine Melo; ROZENDO, Célia Alves. Instituição de longa permanência para idosos: um lugar de cuidado para quem não tem opção? Rev Bras Enferm. 2014;67(5):7739. Disponível em: <http://www.scielo.br/pdf/reben/v67n5/0034-7167-reben-67-05-0773.pdf>

OLIVEIRA, Patrícia Peres de et al. A humanização da assistência na ótica de profissionais de enfermagem que cuidam de idosos*. Investigación en Enfermería: Imagēn y Desarrollo, 2018, 20(2), ISSN: 0124-2059 / 2027-128X. Disponivel em: https://pesquisa.bvsalud.org/portal/resource/pt/biblio-995113.

OLIVEIRA, Paula Beatriz; TAVARES, Darlene Mara dos Santos. Condições de saúde de idosos residentes em Instituição de Longa Permanência segundo necessidades humanas básicas. Rev Bras Enferm. 2014 mar-abr; 67(2): 241-6. Disponivel em: http://www.scielo.br/scielo.php?script=sci_arttext\&pid=S0034-71672014000200241.

Pessini L \& Bertachini L (orgs.). Humanização e cuidados paliativos. EDUNISC-Edições Loyola, São Paulo, 2004, 319 p. Disponível em: <http://www.scielo.br/scielo.php?script=sci_arttext\&pid=S1413-81232005000300035>.

PINHO, Rocilda Castro et al. Assistência de Enfermagem humanizada no atendimento ao idoso para a prevenção e promoção de saúde. 2017. Disponível em: $<$ https://even3.blob.core.windows.net/anais/47845.pdf>.

PREVIATO, Giselle Fernanda et al. Grupo de convivência para idosos na atenção primária à saúde: contribuições para o envelhecimento ativo. Rev Fun Care Online. 2019 jan/mar; 11(1):173-180. Disponível em: <file:///C:/Users/estai/Downloads/6869-40207-2-PB.pdf>.

RODRIGUES, Maria Auxiliadora et al. Exercício profissional de enfermagem em instituições de longa permanência para idosos: estudo retrospectivo. Texto Contexto Enferm, 2018; 27(2):e1700016. Disponivel em: <http://www.scielo.br/pdf/tce/v27n2/0104-0707-tce-27-02e1700016.pdf>.

SANTOS, Silvana Sidney Costa et al. O papel do enfermeiro na instituição de longa permanência para idosos. Rev enferm UFPE on line. 2008 jul./set.; 2(3):291-99. Disponível em: <http://repositorio.furg.br/bitstream/handle/1/1537/PDF\%20n\%C2\%BA\%2018.PDF?sequence=1 $>$.

SILVA, Hélica Pereira; SILVA, Jonh Lennon Soares. Humanização da Assistência de Enfermagem ao idoso. Anápolis Goiás. 2017. Disponível em: <http://fibra.edu.br/wpcontent/uploads/2017/08/TCC-John-Lennon-Silva-e-H\%C3\%A9lica-Silva.pdf>.

VERAS, Renato Peixoto; OLIVEIRA, Martha. Envelhecer no Brasil: a construção de um modelo de cuidado. Ciência e saúde coletiva, 23(6):1929-1936, 2018, Universidade Aberta da Terceira Idade, Instituto de Medicina Social, Universidade do Estado do Rio de Janeiro. Disponivel em: <https://www.scielosp.org/pdf/csc/2018.v23n6/1929-1936/pt>. 